\title{
Bandwidth-Enhanced Low-Profile Antenna with Parasitic Patches
}

\author{
Son Xuat Ta, ${ }^{1}$ Kam Eucharist Kedze, ${ }^{2}$ Dao Ngoc Chien, ${ }^{1}$ and Ikmo Park ${ }^{2}$ \\ ${ }^{1}$ School of Electronics and Telecommunications, Hanoi University of Science and Technology, Hanoi, Vietnam
}

${ }^{2}$ Department of Electrical and Computer Engineering, Ajou University, Suwon, Republic of Korea

Correspondence should be addressed to Ikmo Park; ipark@ajou.ac.kr

Received 27 June 2017; Revised 2 October 2017; Accepted 22 October 2017; Published 6 December 2017

Academic Editor: Ahmed Toaha Mobashsher

Copyright (C) 2017 Son Xuat Ta et al. This is an open access article distributed under the Creative Commons Attribution License, which permits unrestricted use, distribution, and reproduction in any medium, provided the original work is properly cited.

\begin{abstract}
This paper presents low-profile broadband antennas, which are composed of four parasitic patches placed between planar radiators and a perfect electric conductor ground plane. Two types of planar radiators, a conventional dipole and a crossed dipole, are employed to produce linearly polarized (LP) and circularly polarized (CP) radiations, respectively. The radiator and parasitic patches are realized on thin substrates to lower the cost. Owing to the presence of parasitic patches, the antenna performance improves in terms of profile reduction, resonant frequency decrease, and bandwidth enhancement. These improvements are discussed and confirmed computationally and experimentally. The LP design with the overall dimensions of $120 \mathrm{~mm} \times 120 \mathrm{~mm} \times 16.3 \mathrm{~mm}\left(0.64 \lambda_{0} \times 0.64 \lambda_{0} \times 0.087 \lambda_{0}\right.$ at $\left.1.6 \mathrm{GHz}\right)$ has a $\left|\mathrm{S}_{11}\right|<-10 \mathrm{~dB}$ bandwidth of $1.465-1.740 \mathrm{GHz}(17.2 \%)$, a broadside gain of $8.5-8.8 \mathrm{dBi}$, and a radiation efficiency $>96 \%$. The CP design, which has the same physical size as the LP case, has a $\left|\mathrm{S}_{11}\right|<-10 \mathrm{~dB}$ bandwidth of $1.388-1.754 \mathrm{GHz}$ (23.3\%), a $3 \mathrm{~dB}$ AR (axial ratio) bandwidth of $1.450-1.685 \mathrm{GHz}(15.0 \%)$, a right-hand $\mathrm{CP}$ broadside gain of 7.8-8.7 $\mathrm{dBic}$, and a radiation efficiency $>90 \%$.
\end{abstract}

\section{Introduction}

The dipole antenna, which has the simplest configuration, is the most widely used antenna in radio, broadcasting, and wireless communication systems. This antenna is commonly composed of two identical metallic elements, such as wires, rods, or printed strips, which are usually symmetrically arranged. In free-space, a dipole antenna exhibits an omnidirectional radiation pattern. In order to direct the electromagnetic energy in the desired direction and improve the gain, the dipole antenna is generally equipped with a metallic reflector. Since the image current of the dipole placed horizontally above a metallic reflector is different from the $180^{\circ}$ with the current on the dipole, the antenna system requires an approximately $\lambda / 4$ distance between the dipole and reflector for optimal performances. If the distance is reduced, the image currents on the metallic reflector tend to cancel out the radiation from the dipole, and consequently the antenna performance is degraded significantly.

Several methods have been proposed to improve the performance of dipoles that are very closely placed above a metallic ground. The first method is to modify the dipole itself to increase the radiation resistance for better impedance matching. As an example, a multiple arm-folded dipole antenna above a ground plane with a height of $0.02 \lambda_{0}$ achieves a voltage standing wave ratio (VSWR) $<3$, a bandwidth of $2.2 \%$, an efficiency of $97 \%$, and a broadside gain of $8.7 \mathrm{dBi}[1]$. The second method is to place the dipole above an artificial surface [2-10]. These artificial structures, which are generally composed of a periodic array of metal patches on a grounded dielectric substrate with/without vias, have been designed to mimic a perfect magnetic conductor with a zero-phase shift at certain frequency bands and consequently enable the placement of a dipole having good impedance matching and radiation efficiency in close proximity. However, the artificial surface operating at a low frequency requires a thick substrate, which significantly increases not only the fabrication cost but also the volume of the antenna. Recently, a method of inserting a parasitic strip between the horizontal dipole above the ground plane at a low profile $\left(0.05 \lambda_{0}\right)$ [11] has been reported to achieve a good broadside radiation with a gain of $7.8 \mathrm{dBi}$ and an efficiency of $74 \%$. 


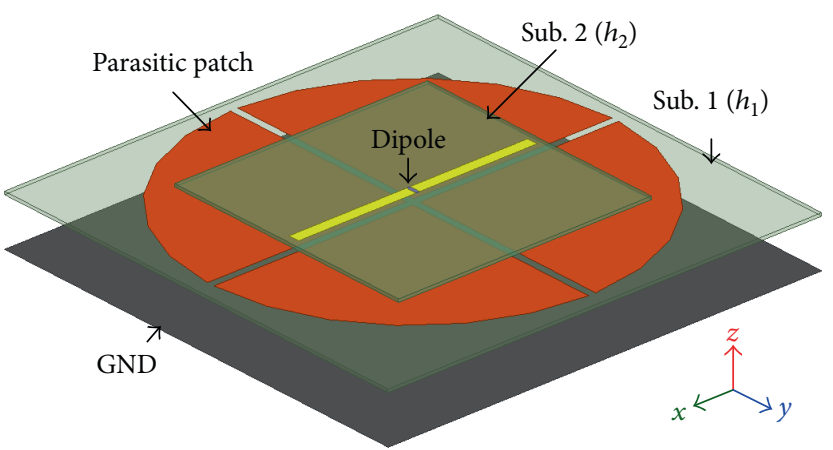

(a)

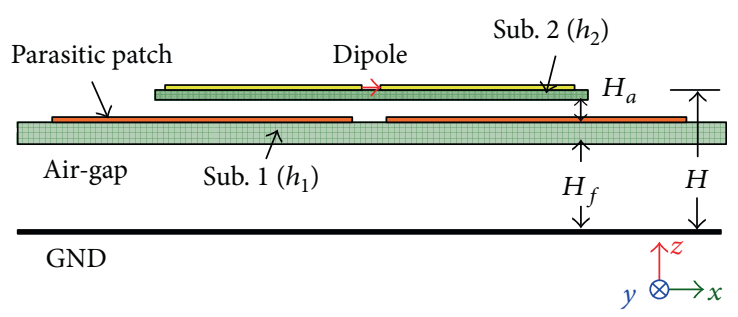

(b)

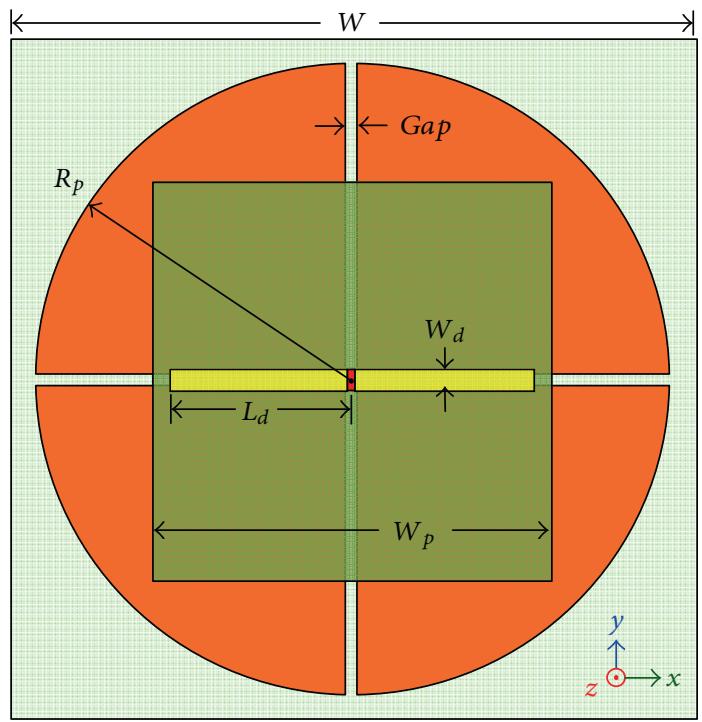

(c)

Figure 1: Geometry of a printed dipole loaded with parasitic patches: (a) perspective view, (b) side view, and (c) top view.

However, its impedance matching bandwidth is very narrow; that is, $0.6 \%$

On the other hand, a single-feed crossed-dipole antenna is a common, modern antenna used to produce circularly polarized (CP) radiation [12]. CP radiation is obtained when the length of the dipoles satisfies the following conditions: the real parts of their input admittances are equal and the phase angles of their input admittances differ by $90^{\circ}$ [13]. In free-space, a conventional crossed dipole produces bidirectional CP radiation in the broadside directions. In order to redirect a half of the radiation into the opposite direction, the crossed-dipole antennas are generally horizontally placed on a metallic reflector [14]. In addition, the operational bandwidth of conventional crossed dipoles can be broadened by loading parasitic elements $[15,16]$ or by using an enlarged dipole $[17,18]$. However, the crossed-dipole antennas equipped with a metallic reflector suffers from a large profile, which is approximately $\lambda / 4$. This problem has been overcome by using an artificial surface instead of the metallic reflector, see [12] and the references therein. Further, several studies have demonstrated that surface waves propagating on a finite artificial surface when excited generate extra CP radiation for the crossed-dipole antenna, which can be employed for extending the antenna bandwidth [19-21]. However, as mentioned earlier, the realization of an artificial surface for low-frequency applications has a high cost because an electrically thick substrate is required.

This paper investigates low-cost, low-profile broadband antennas, which are composed of four parasitic patches inserted between planar radiators and a ground plane. Two types of antennas are investigated: the first one is a single-dipole antenna for LP radiation, and the other is a single-feed crossed-dipole antenna for CP radiation. The radiators and parasitic patches are implemented on thin substrates to lower the fabrication cost. Owing to the presence of the parasitic patches, the antenna achieves profile reduction, shifting resonance toward the lower frequency and broadening the bandwidth. These advantages were first computationally determined using the frequency domain ANSYS/ANSOFT high-frequency structure simulator (HFSS) and subsequently confirmed experimentally.

\section{Single-Dipole Antenna Loaded with Parasitic Patches}

2.1. Antenna Geometry. Figure 1 shows the geometry of a single-dipole antenna loaded with parasitic patches. The antenna comprises a center-fed printed dipole, four parasitic 


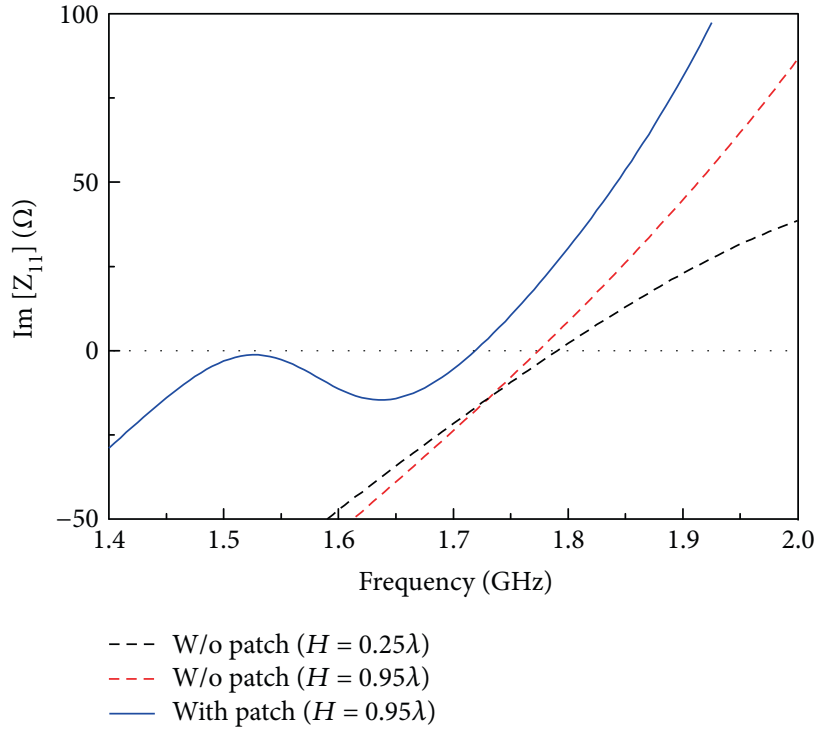

(a)

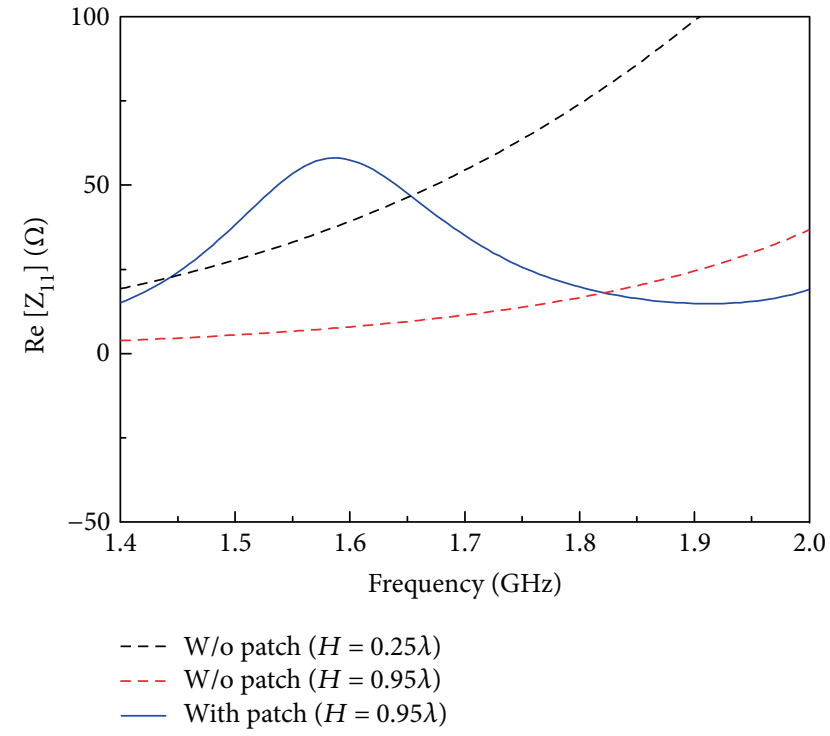

(b)

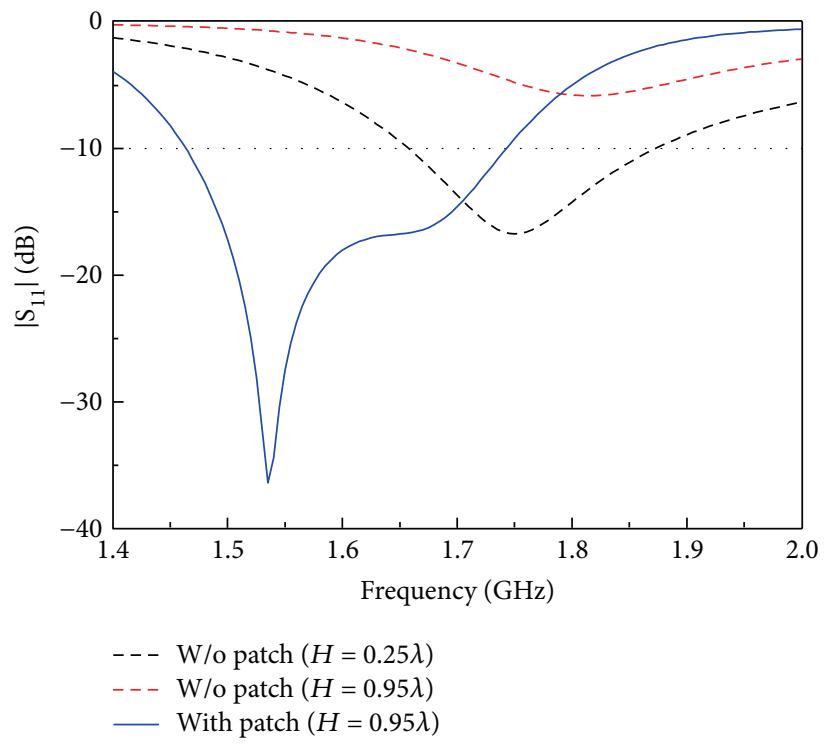

(c)

Figure 2: Simulated (a) imaginary part of $Z_{11}$, (b) real part of $Z_{11}$, and (c) $\left|S_{11}\right|$ values of the single-dipole antenna in different configurations ( $\lambda$ is the free-space wavelength at $1.75 \mathrm{GHz}$ ).

patches, a ground plane, and two dielectric substrates. The parasitic patches and dipole were printed on the top side of substrate 1 and substrate 2 , respectively. The two substrates, made of Rogers RO4003 material $\left(\varepsilon_{\mathrm{r}}=3.38, \tan \delta=0.0027\right.$, and $h_{1}=h_{2}=0.8128 \mathrm{~mm}$ ), were placed horizontally above the ground plane and close to it. The parasitic patches were formed by quartering a circular patch via two orthogonal slots. The antenna was characterized via the ANSYS HFSS to obtain a low profile and a broadband characteristic at a frequency of $1.6 \mathrm{GHz}$. The antenna was excited by a perfect lump-port with an input impedance of $50 \Omega$. The antenna's optimized design parameters are as follows: $W=120 \mathrm{~mm}, H_{\mathrm{f}}=12.7 \mathrm{~mm}, H_{\mathrm{a}}=$ $2 \mathrm{~mm}, W_{\mathrm{p}}=70 \mathrm{~mm}, R_{\mathrm{p}}=56 \mathrm{~mm}$, gap $=2 \mathrm{~mm}, L_{\mathrm{d}}=33 \mathrm{~mm}$, $W_{\mathrm{d}}=3 \mathrm{~mm}, h_{1}=h_{2}=0.8128 \mathrm{~mm}$, and $H=16.3 \mathrm{~mm}$.
2.2. Antenna Miniaturization and Bandwidth Improvement. As mentioned earlier, the parasitic patches are placed between the horizontal dipole and the ground plane in order to achieve profile miniaturization and bandwidth improvement. This is demonstrated in Figure 2, which shows the simulated input impedances and $\left|S_{11}\right|$ values of the single-dipole antenna in different configurations. The first configuration is the single-dipole antenna without parasitic patches, which is placed above the ground plane at a height of $H=43.6 \mathrm{~mm}$ (approximate $0.25 \lambda$ at $1.75 \mathrm{GHz}$ ). For the second configuration, the height of the first configuration $(43.6 \mathrm{~mm})$ is reduced to $H=16.3 \mathrm{~mm}$ (approximate $0.095 \lambda$ at $1.75 \mathrm{GHz}$ ). The third configuration is the proposed design with the parasitic patches between the dipole antenna and the ground 


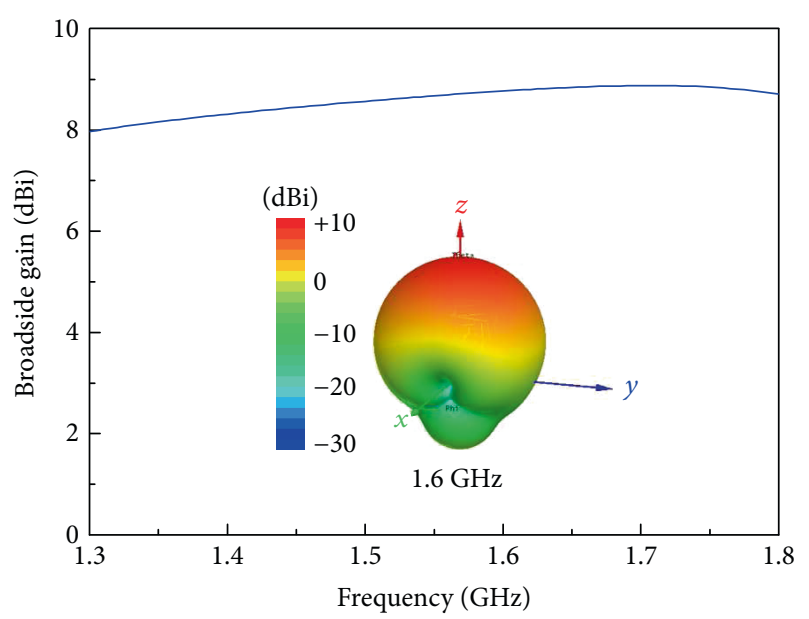

(a)

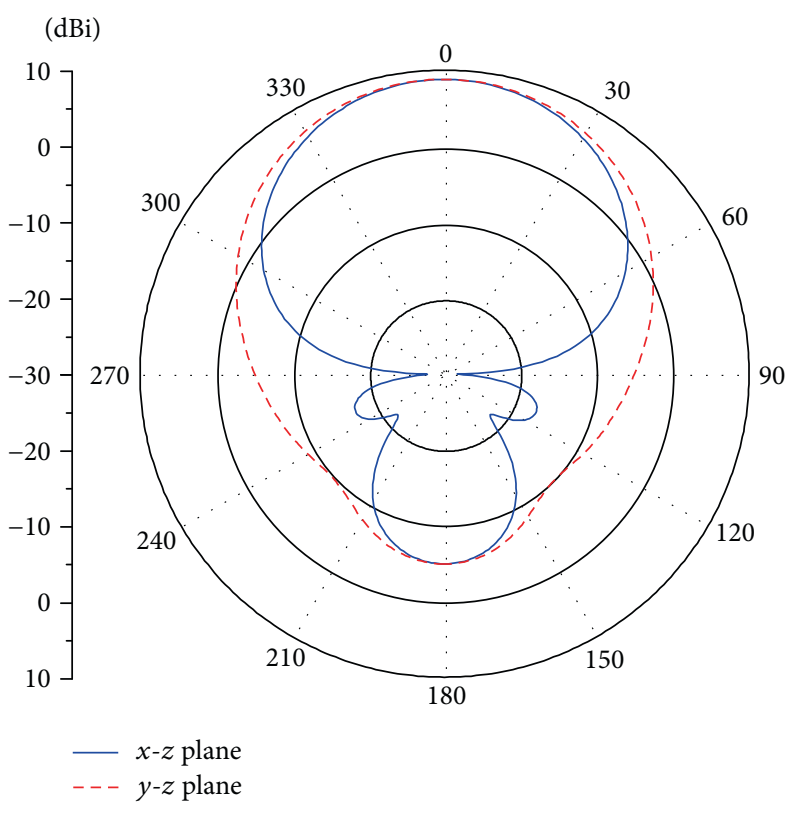

(b)

FIGURE 3: Simulations of the single-dipole antenna loaded with parasitic patches: (a) broadside gain, together with 3D 1.6 GHz total-gain pattern and (b) $2 \mathrm{D} 1.6 \mathrm{GHz}$ radiation pattern.

plane and $H=16.3 \mathrm{~mm}$. The other parameters of the first and second configurations are the same as those of the third configuration presented in Figure 1.

As shown in Figures 2(a) and 2(b), the first configuration resonated at $1.79 \mathrm{GHz}$ with an input resistance of $71.8 \Omega$, whereas the second configuration yielded an input resistance of $15.1 \Omega$ at its resonant frequency of $1.775 \mathrm{GHz}$. It is observed that the minimized profile of the antenna is accompanied by a significant reduction in the input resistance. Therefore, the second configuration does not match well with the standard input impedance of $50 \Omega$. As considered to their $\left|S_{11}\right|$ profiles in Figure 2(c), the first configuration yielded a $\left|\mathrm{S}_{11}\right|<-10 \mathrm{~dB}$ bandwidth of $1.66-1.87 \mathrm{GHz}$ (11.9\%) with one minimum point at $1.75 \mathrm{GHz}$, whereas the second configuration yielded a minimum $\left|\mathrm{S}_{11}\right|$ of $-5.84 \mathrm{~dB}$ at $1.815 \mathrm{GHz}$. The proposed design yielded two resonant frequencies at $1.525 \mathrm{GHz}$ and $1.72 \mathrm{GHz}$ with input resistances of $46.4 \Omega$ and $30.9 \Omega$, respectively. It is observed that the resonant frequencies of the proposed antenna are lower than those of other configurations. Furthermore, the antenna can be readily matched to the $50 \Omega$ source directly at both resonant frequencies. As shown in Figure 2(c), the proposed design with an overall size of $120 \mathrm{~mm} \times 120 \mathrm{~mm} \times 16.3 \mathrm{~mm}$ $\left(0.64 \lambda_{\mathrm{o}} \times 0.64 \lambda_{\mathrm{o}} \times 0.087 \lambda_{\mathrm{o}}\right.$ at $\left.1.6 \mathrm{GHz}\right)$ yielded a $\left|\mathrm{S}_{11}\right|<-10 \mathrm{~dB}$ bandwidth of $1.465-1.740 \mathrm{GHz}(17.2 \%)$ with two minimum points at $1.535 \mathrm{GHz}$ and $1.66 \mathrm{GHz}$. As compared to the conventional design (the first configuration), the proposed antenna has a lower profile, a lower operating frequency, and a broader bandwidth. As a result, the presence of the parasitic patches produces antenna miniaturization and operational bandwidth improvement for the horizontal dipole antenna above the ground plane and close to it.

The radiation performance of the single dipole loaded with parasitic patches was characterized and is shown in
Figure 3. Owing to the use of the single-dipole radiator, the antenna radiated an LP electromagnetic wave; it generated a good broadside radiation with a symmetric profile, small gain variation, and a high front-to-back ratio. For example, at $1.6 \mathrm{GHz}$, it produced a broadside gain of $8.77 \mathrm{dBi}$, half-power beamwidths (HPBWs) of $62^{\circ}$ and $74^{\circ}$ in the $x-z$ and $y-z$ planes, respectively, and a front-toback ratio of $13.72 \mathrm{~dB}$. In addition, the HFSS simulations indicate that the antenna yielded a broadside gain of $8.5-8.8 \mathrm{dBi}$ and a radiation efficiency $>96 \%$ across its operational bandwidth.

In order to qualitatively explain the antenna operation mechanism, the surface current distribution on the singledipole antenna loaded with parasitic patches was calculated and given in Figure 4. It is observed that the presence of the parasitic patches changes the role of the dipole; that is, in the proposed structure, the dipole acts not only as the radiating element but also as the antenna feeder to the vertical slot that also acts as the radiating element. In addition, the currents at the horizontal edges of the parasitic patches are out of phase with the current on the dipole. This confirms that the patches change the phase of the electric field between the dipole and the reflector, consequently minimizing their mutual coupling.

In [11], the insertion of a straight parasitic strip between the dipole and the reflector produced two resonances for the antenna system. However, at its first resonance, the antenna does not match to the $50 \Omega$ source due to the $3 \Omega$ input resistance. Different from [11], the proposed antenna employed four parasitic patches inserted between the dipole and the reflector to increase the input resistance at the first resonance, consequently allowing for the antenna to nearly completely match to the $50 \Omega$ source at both resonant frequencies. Accordingly, the antenna bandwidth is improved. 


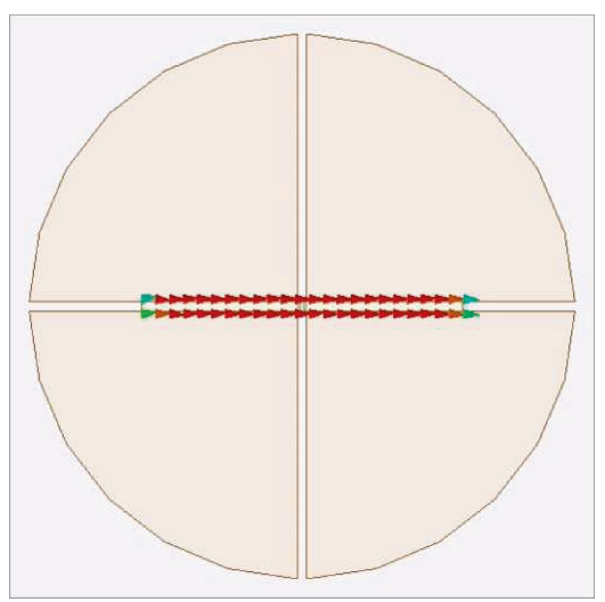

(a)



(b)

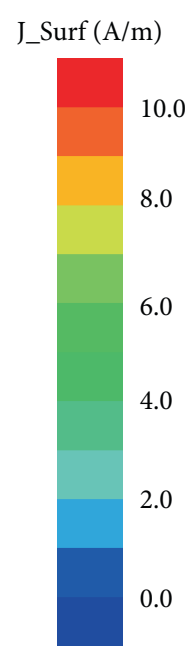

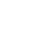

FIGURE 4: Surface current distributions on (a) single dipole and (b) parasitic patches at $1.6 \mathrm{GHz}$.

TABle 1: Performance comparison of the dipole antennas with parasitic elements.

\begin{tabular}{lcccc}
\hline Structure & Profile & $\begin{array}{c}\left|\mathrm{S}_{11}\right|<-10 \mathrm{~dB} \\
\text { bandwidth }\end{array}$ & Gain & $\begin{array}{c}\text { Radiation } \\
\text { efficiency }\end{array}$ \\
\hline Proposed & $0.087 \lambda$ & $17.2 \%$ & $8.8 \mathrm{dBi}$ & $96 \%$ \\
Ref. [11] & $0.050 \lambda$ & $0.6 \%$ & $7.8 \mathrm{dBi}$ & $74 \%$ \\
\hline
\end{tabular}

$\lambda$ is the free-space wavelength referring to the center frequency.

This has been demonstrated in Figure 2 and discussed in the previous section.

In order to clarify the features of the proposed antenna, a performance comparison between the low-profile dipole antennas based on parasitic elements has been carried out and is provided in Table 1. It is observed that both antennas yielded a low profile of $<0.1 \lambda$, but the proposed design has a significantly wider $\left|S_{11}\right|<-10 \mathrm{~dB}$ impedance bandwidth, higher gain, and better radiation efficiency.

2.3. Parametric Studies. For better understanding of the radiation mechanism of the single-dipole antenna loaded with parasitic patches, we carried out parametric studies for some key parameters of the structure; that is, its input impedance was examined by changing only one parameter at a time and fixing all other design parameters.

Figure 5 shows the input impedance of the antenna for different radii of the parasitic patches $\left(R_{\mathrm{p}}\right)$. As $R_{\mathrm{p}}$ increased, the length of the slot between the patches was increased. Accordingly, the resonances of the antenna shifted toward the lower frequency. This indicates that the size of the parasitic patch $\left(R_{\mathrm{p}}\right)$ is a crucial design parameter for determining the operating frequency of the antenna.

As revealed in the previous section, the horizontal slot between parasitic patches acts as the primary radiating element of the antenna. Similar to a slotted antenna, the slot width mainly affects the input impedance. This is observed in Figure 6, which shows the input impedance and $|S 11|$ values of the antenna for different spacing between parasitic patches (gap). As shown in Figure 6(a), both input resistance and reactance are proportional to the spacing (gap). Accordingly, the impedance matching can be obtained by adjusting gap, as shown in Figure 6(b).

As shown in Figure 7, by varying distance between the parasitic patches and the ground plane from $H_{\mathrm{f}}=10 \mathrm{~mm}$ to $15.4 \mathrm{~mm}$, the antenna profile increased. Therefore, the resonances shifted toward the lower frequency. On the other word, with $H_{\mathrm{f}}$ increasing, the input resistance and input reactance of the antenna decreased, which degraded the impedance matching. The $H_{\mathrm{f}}=12.7 \mathrm{~mm}$ was chosen for the final design based on the trade-off between the antenna minimization and the good impedance matching.

As mentioned above, the single dipole in the proposed configuration acts as the antenna feed; therefore, the design parameters and position of the dipole hardly affect the antenna resonances. This is demonstrated in Figures 8 and 9 , which show the input impedance and $\left|S_{11}\right|$ values of the antenna for different lengths of the dipole arm $\left(L_{\mathrm{d}}\right)$ and spacing $\left(H_{\mathrm{a}}\right)$ between the dipole radiator and the parasitic patches. As shown in Figure 8, with an increase of $L_{\mathrm{d}}$, the input reactance of the antenna increased significantly, whereas its input resistance and resonant varied minimally. In Figure 9, by increasing $H_{\mathrm{a}}=1 \mathrm{~mm}$ to $3 \mathrm{~mm}$, the input resistance and resonant frequencies of the antenna slightly changed, whereas its input reactance decreased significantly. These results indicate that $L_{\mathrm{d}}$ and $H_{\mathrm{a}}$ are the crucial parameters of impedance matching for the proposed antenna.

\section{Crossed-Dipole Antenna Loaded with Parasitic Patches}

The previous section has demonstrated that the parasitic patches produce a profile reduction and an operational bandwidth improvement for a low-profile LP antenna composed of a horizontal dipole antenna placed above the ground plane and close to it. In this section, these features are further validated for a CP antenna by utilizing a single-feed crossed-dipole instead of the horizontal dipole. 


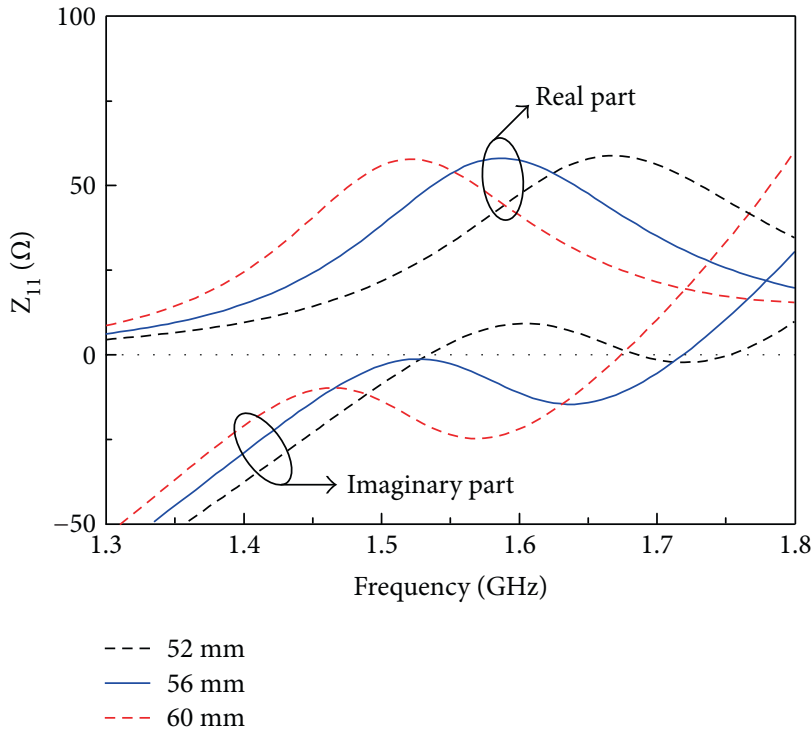

(a)



(b)

Figure 5: Simulated (a) input impedance and (b) $\left|S_{11}\right|$ values of the single-dipole antenna loaded with parasitic patches for different sizes of the parasitic patch $\left(R_{\mathrm{p}}\right)$.

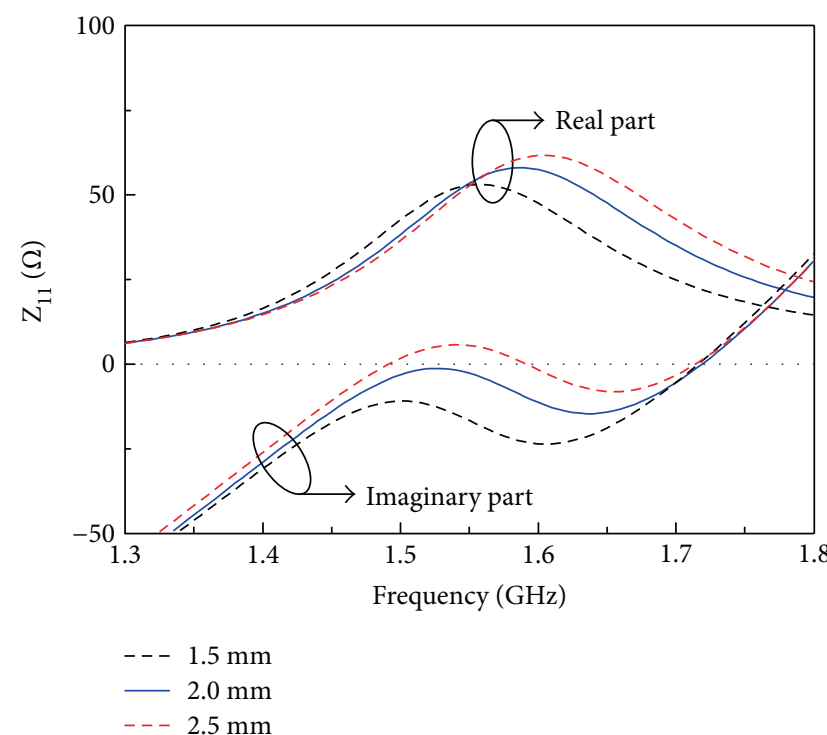

(a)



(b)

FIGURE 6: Simulated (a) input impedance and (b) $\left|S_{11}\right|$ values of the single-dipole antenna loaded with parasitic patches for different spacings between parasitic patches (gap).

3.1. Antenna Geometry. Figure 10 shows the geometry of a crossed-dipole antenna loaded with parasitic patches. The antenna comprises a single-feed crossed-dipole, four parasitic patches, a ground plane, two dielectric substrates, a coaxial line, and a $50 \Omega$ subminiature version A (SMA) connector. The parasitic patches were printed on the top side of substrate 1 . The crossed dipoles were built on both sides of substrate 2 and are directly fed by the $50 \Omega$ coaxial line [12]. The crossed dipoles included double vacant quarter-printed rings to produce the $\mathrm{CP}$ radiation. The two substrates were made of Rogers RO4003 material $\left(\varepsilon_{\mathrm{r}}=3.38\right.$ and $\left.\tan \delta=0.0027\right)$. Similar to the LP design, the parasitic patches of the CP antenna were formed by quartering a circular patch via two orthogonal slots. The crossed-dipole antenna loaded with parasitic patches was optimized with a series of the HFSS simulations to obtain a low profile, good impedance matching, and $\mathrm{CP}$ radiation at a frequency of $1.6 \mathrm{GHz}$. Its design 




(a)

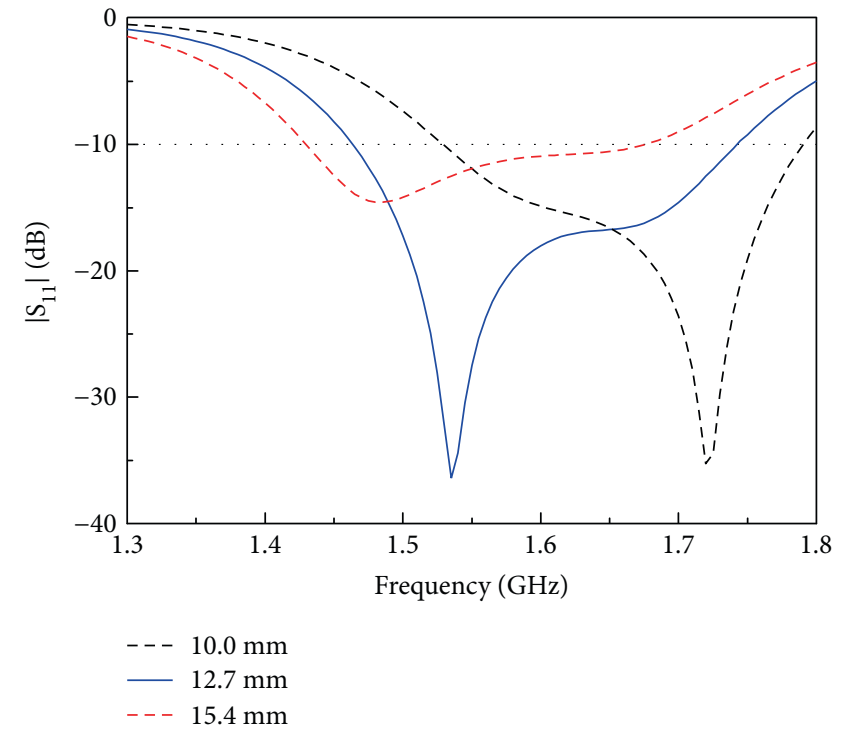

(b)

FIGURE 7: Simulated (a) input impedance and (b) $\left|S_{11}\right|$ values of the single-dipole antenna loaded with parasitic patches for different distances from the ground plane to the parasitic patches $\left(H_{\mathrm{f}}\right)$.

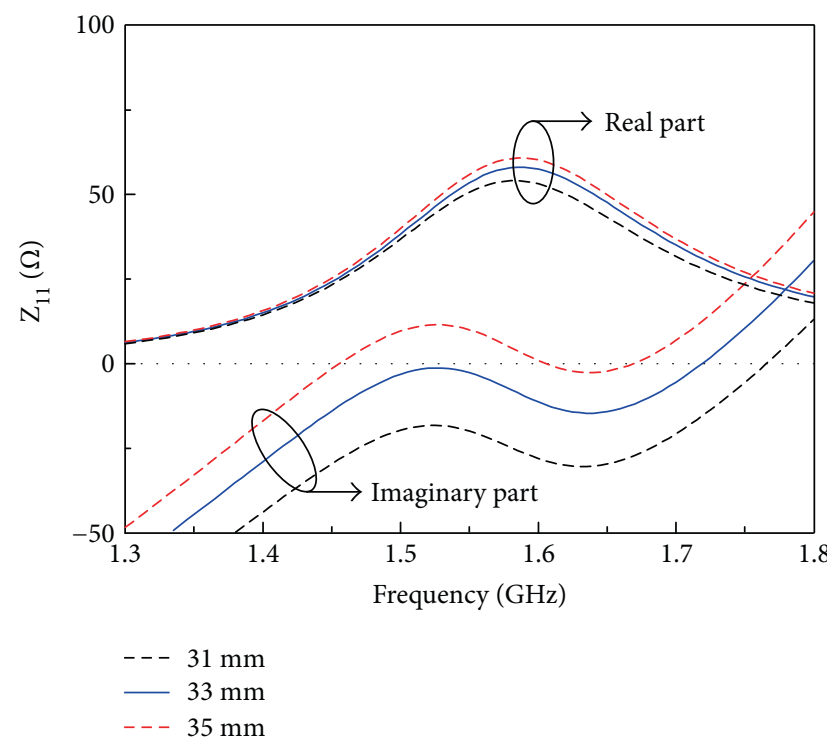

(a)

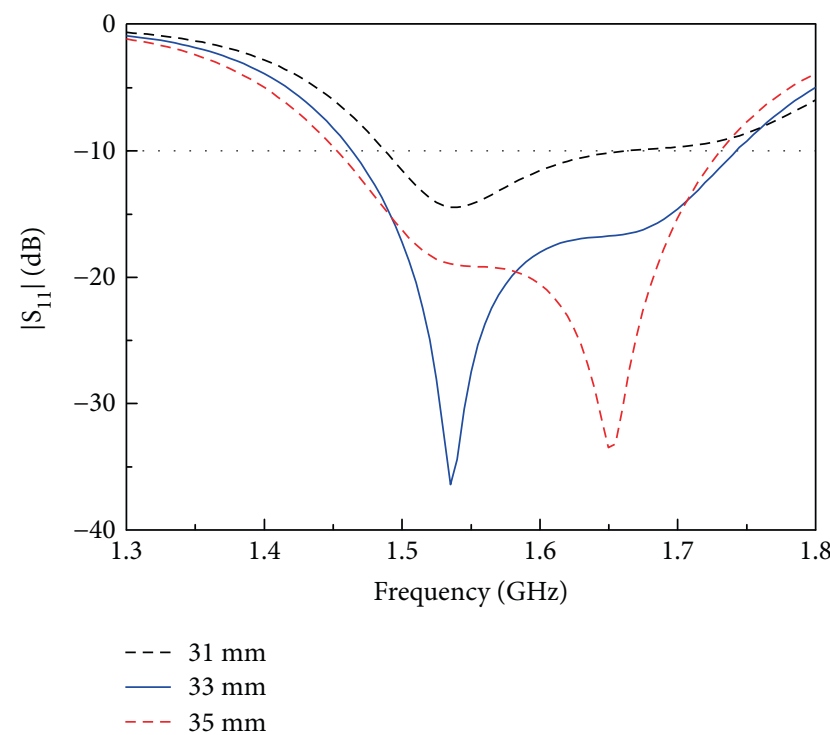

(b)

Figure 8: Simulated (a) input impedance and (b) $\left|S_{11}\right|$ values of the single-dipole antenna loaded with parasitic patches for different dipole lengths $\left(L_{\mathrm{d}}\right)$.

parameters are as follows: $W=120 \mathrm{~mm}, H_{\mathrm{f}}=12.7 \mathrm{~mm}, H_{\mathrm{a}}=$ $2 \mathrm{~mm}, W_{\mathrm{p}}=70 \mathrm{~mm}, R_{\mathrm{p}}=56 \mathrm{~mm}$, gap $=2 \mathrm{~mm}, L_{\mathrm{d}}=33 \mathrm{~mm}$, $W_{\mathrm{d}}=3 \mathrm{~mm}, R_{\mathrm{i}}=4 \mathrm{~mm}, W_{\mathrm{r}}=0.8 \mathrm{~mm}, h_{1}=h_{2}=0.8128 \mathrm{~mm}$, and $H=16.3 \mathrm{~mm}$.

\subsection{Antenna Miniaturization and Bandwidth Improvement.} As mentioned earlier, the parasitic patches are placed between the crossed-dipole antenna and the ground plane to achieve antenna minimization and bandwidth improvement. This is proved in Figure 11, which shows simulated performances of crossed-dipole antennas in different configurations, including three cases. First, the crossed-dipole antenna without parasitic patches is placed above the ground plane at a height of $H=43.6 \mathrm{~mm}$ (approximately $0.24 \lambda$ at $1.65 \mathrm{GHz}$ ). In the second case, the height $H=43.6 \mathrm{~mm}$ of the first case is reduced to $H=16.3 \mathrm{~mm}$ (approximate $0.09 \lambda$ at $1.65 \mathrm{GHz}$ ). The third case is the crossed-dipole antenna with parasitic patches and $H=16.3 \mathrm{~mm}$ (approximate $0.09 \lambda$ at $1.65 \mathrm{GHz}$ ). The design parameters of all cases are the same as those of the antenna presented in Figure 10. 


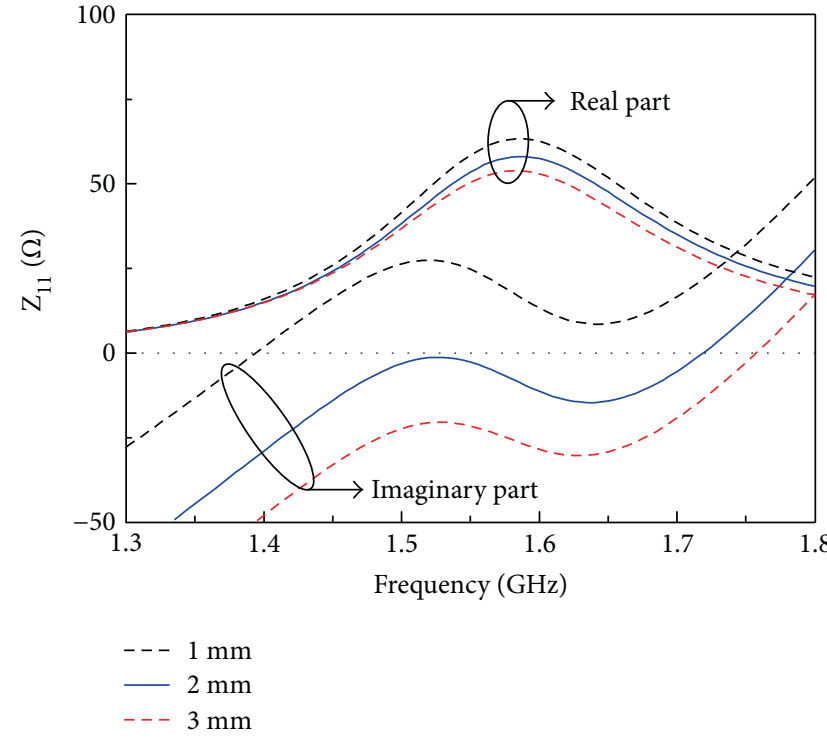

(a)

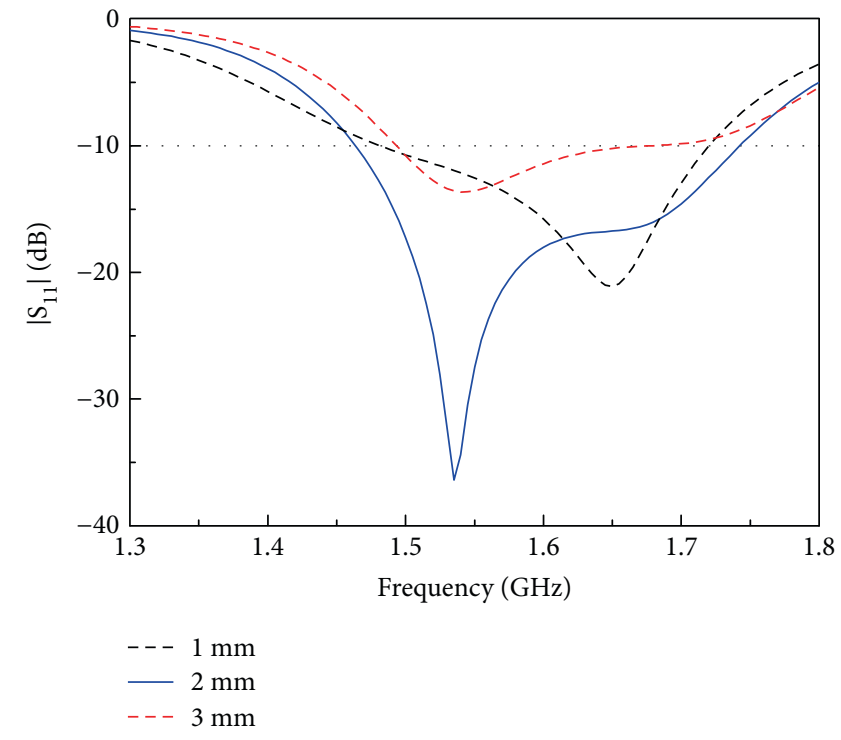

(b)

FIGURE 9: Simulated (a) input impedance and (b) $\left|S_{11}\right|$ values of the single-dipole antenna loaded with parasitic patches for different spacings between the dipole radiator and the parasitic patch $\left(H_{\mathrm{a}}\right)$.

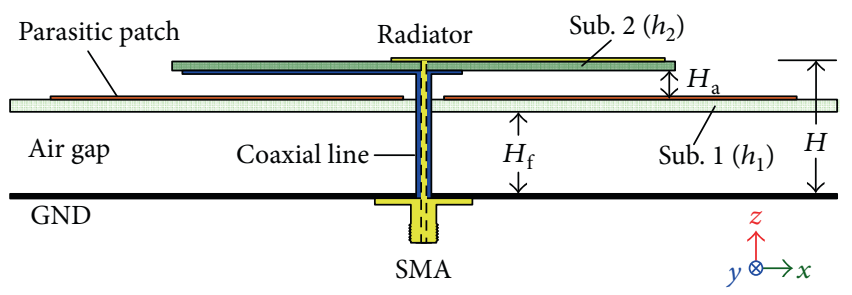

(a)

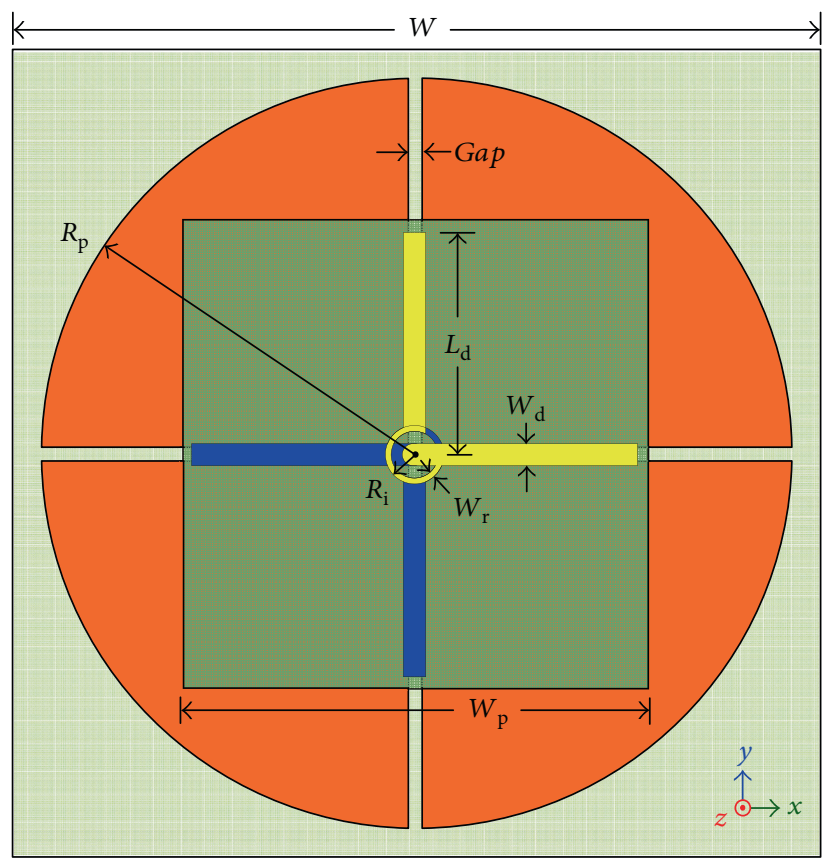

(b)

FIGURE 10: Geometry of the proposed antenna: (a) cross-sectional view and (b) top view.
As shown in Figure 11, the first configuration with $H=0.24 \lambda$ yielded the almost fully optimized results of a conventional crossed dipole; its $\left|\mathrm{S}_{11}\right|<-10 \mathrm{~dB}$ bandwidth was $1.550-2.155 \mathrm{GHz}(32.6 \%)$, and its $3-\mathrm{dB}$ axial ratio (AR) bandwidth was $1.605-1.725 \mathrm{GHz}(7.2 \%)$ with one $\mathrm{CP}$ center frequency at $1.66 \mathrm{GHz}(\mathrm{AR}=0.83 \mathrm{~dB})$. It is observed that the minimized profile of the antenna is accompanied by significant degradation in the antenna performance. The second configuration with $H=0.09 \lambda$ did not match the $50 \Omega$ coaxial line well, and therefore its $\left|\mathrm{S}_{11}\right|<-10 \mathrm{~dB}$ bandwidth was $1.690-1.755 \mathrm{GHz}$ (3.8\%). In addition, the second case yielded zero $3 \mathrm{~dB}$ bandwidth with one $\mathrm{CP}$ center frequency at $1.785 \mathrm{GHz}(\mathrm{AR}=12.0 \mathrm{~dB})$. Owing to the presence of the parasitic patches, although the profile of $H=0.09 \lambda$ remained at $1.65 \mathrm{GHz}$, the operational frequency of the crossed-dipole antenna shifted toward the lower frequency, and its operational bandwidth significantly improved. Here, the operational bandwidth is defined as the frequency range where the antenna yields a $\left|S_{11}\right|<-10 \mathrm{~dB}$ and $\mathrm{AR}<3 \mathrm{~dB}$. The design with parasitic patches yielded a $\left|S_{11}\right|<-10 \mathrm{~dB}$ bandwidth of $1.39-1.75 \mathrm{GHz}(22.93 \%)$ and a $3 \mathrm{~dB}$ AR bandwidth of $1.472-1.684 \mathrm{GHz}(13.4 \%)$ with two $\mathrm{CP}$ center frequencies at $1.52 \mathrm{GHz}(\mathrm{AR}=1.6 \mathrm{~dB})$ and $1.64 \mathrm{GHz}(\mathrm{AR}=1.5 \mathrm{~dB})$. These results indicate that the insertion of the parasitic patches between the crossed-dipole antenna and the ground plane produced antenna miniaturization and improved the $3 \mathrm{~dB}$ AR bandwidth.

3.3. Measurements. For verification, the crossed-dipole antenna loaded with parasitic patches was fabricated and measured. The crossed dipole and the parasitic patches were printed on Rogers $\mathrm{RO} 4003$ substrates with $0.017 \mu \mathrm{m}$ copper thickness via a standard wet etching technology. Figure 12 shows a fabricated sample of the prototype, which has an overall size of $120 \mathrm{~mm} \times 120 \mathrm{~mm} \times 16.3 \mathrm{~mm}$ 


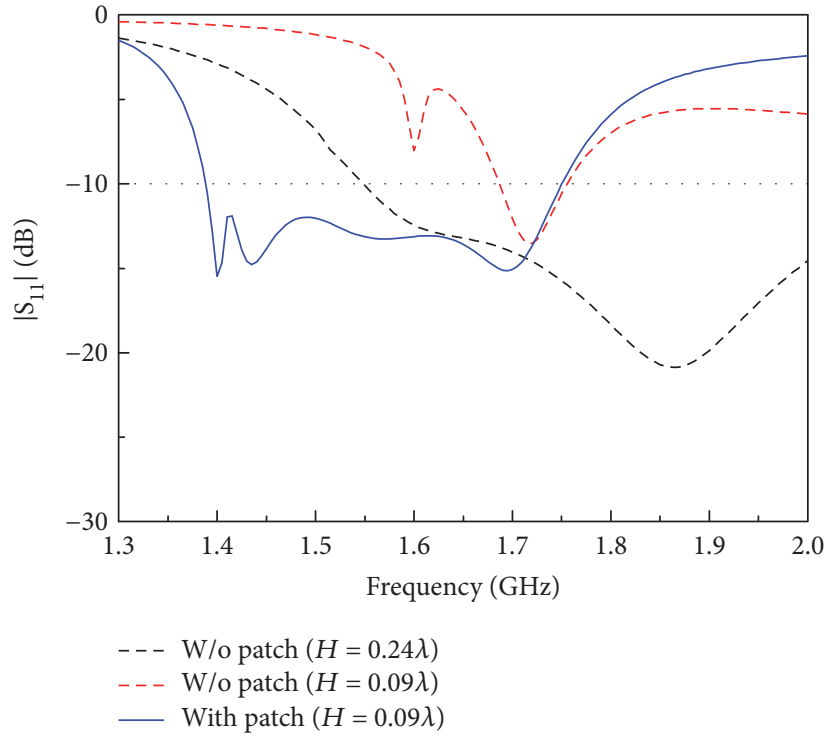

(a)

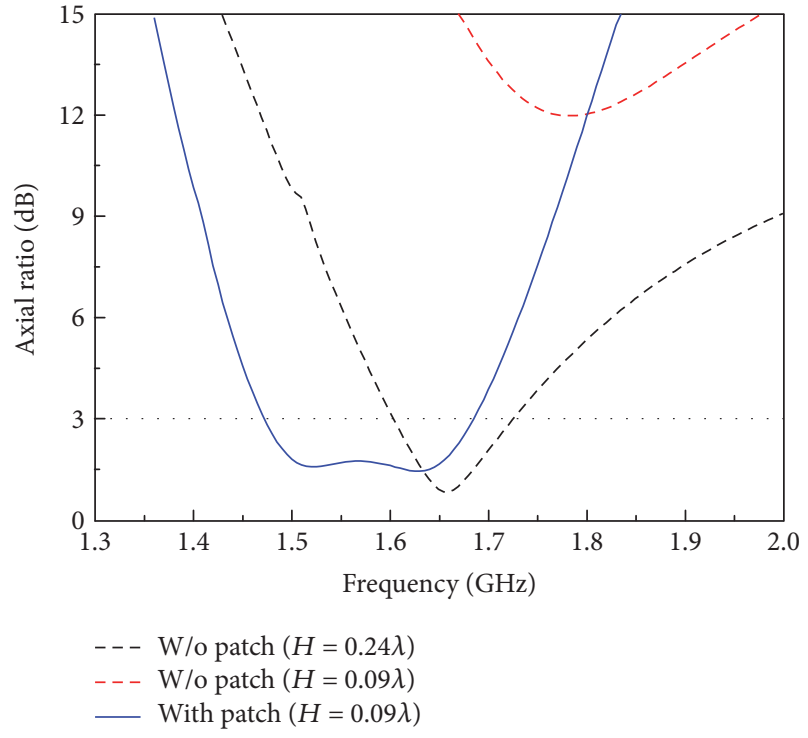

(b)

FIgURE 11: Simulated (a) $\left|S_{11}\right|$ and (b) AR values of the crossed-dipole antennas in different configurations ( $\lambda$ is the free-space wavelength at $1.65 \mathrm{GHz}$ ).

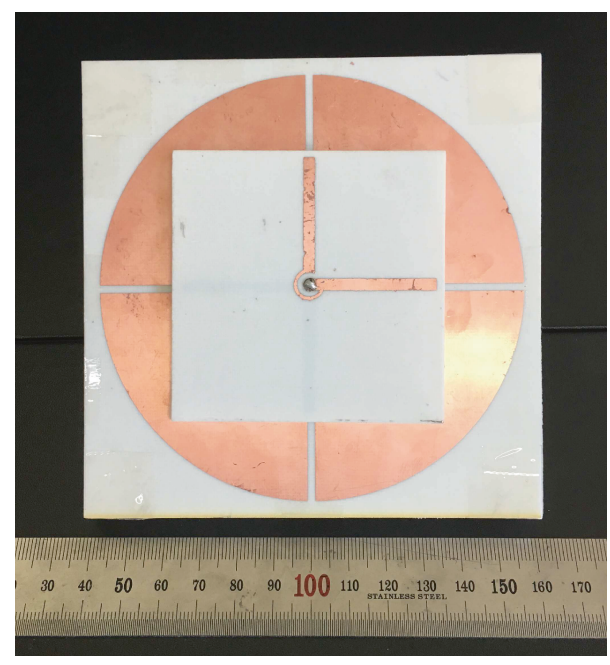

(a)

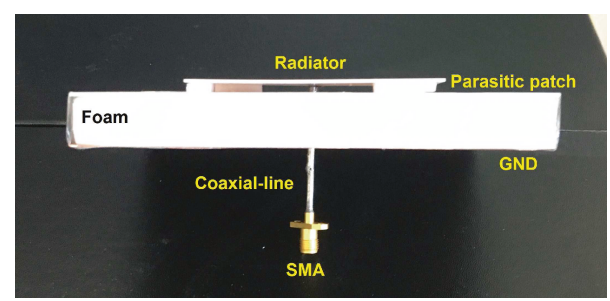

(b)

FIGURE 12: Fabricated sample of the crossed-dipole antenna loaded with parasitic patches: (a) top view and (b) side view.

$\left(0.64 \lambda_{\mathrm{o}} \times 0.64 \lambda_{\mathrm{o}} \times 0.087 \lambda_{\mathrm{o}}\right.$ at $\left.1.6 \mathrm{GHz}\right)$. A structural foam $\left(\varepsilon_{\mathrm{r}}=1.07, \mu_{\mathrm{r}}=1\right.$, and $\left.\tan \delta=0.0006\right)$ with dimensions of $100 \mathrm{~mm} \times 100 \mathrm{~mm} \times 12.7 \mathrm{~mm}$ was sandwiched between substrate 1 and the ground plane to support the antenna structure. Four foam pieces were inserted between substrates 1 and 2 to support the crossed-dipole radiator. For ease of fabrication, we used thin tapes to fasten the components of the fabricated antenna.

Figures 13 and 14 show a comparison between the measured and simulated results of the fabricated antenna. It is observed that the measurements agreed rather closely with the HFSS simulations. As shown in Figure 13(a), the measured $\left|\mathrm{S}_{11}\right|<-10 \mathrm{~dB}$ bandwidth was $1.388-1.754 \mathrm{GHz}$ $(23.3 \%)$, while the simulated value was $1.39-1.75 \mathrm{GHz}$ $(22.93 \%)$. As shown in Figure 13(b), the measurement resulted in a $3 \mathrm{~dB}$ AR bandwidth was $1.450-1.685 \mathrm{GHz}$ (15.0\%), whereas the simulated $3 \mathrm{~dB}$ AR bandwidth was $1.472-1.684 \mathrm{GHz}$ (13.4\%). In addition, Figure 13(b) shows the measured and simulated broadside gains of the prototype. Within the $3 \mathrm{~dB}$ AR bandwidth, the measured broadside gain was $7.8-8.7 \mathrm{dBic}$ compared to the simulated value of $8.43-8.83 \mathrm{dBic}$. There is a slight difference between the measurement and simulation results, which could be attributed the effects of the foams and thin tapes in the fabricated prototype (not included in the simulations).

Figure 14 shows the radiation patterns of the fabricated antenna at $1.52 \mathrm{GHz}$ and $1.64 \mathrm{GHz}$. Both measurement and simulation indicate that the antenna yields good right-hand $\mathrm{CP}$ radiation with a highly symmetric profile in both the $x-z$ and $y-z$ planes. At $1.52 \mathrm{GHz}$, the measurements resulted in a gain of $8.0 \mathrm{dBic}$, a front-to-back ratio of $15.0 \mathrm{~dB}$, and HPBWs of $66^{\circ}$ and $69^{\circ}$ in the $x-z$ and $y-z$ planes, respectively. At $1.64 \mathrm{GHz}$, the measurements yielded a gain of $7.96 \mathrm{dBic}$, a front-to-back ratio of $13.0 \mathrm{~dB}$, and HPBWs of $66^{\circ}$ and $61^{\circ}$ in the $x-z$ and $y-z$ planes, respectively. In addition, the measurement yielded a radiation efficiency $>90 \%$ compared to the simulated value of $>96 \%$. 


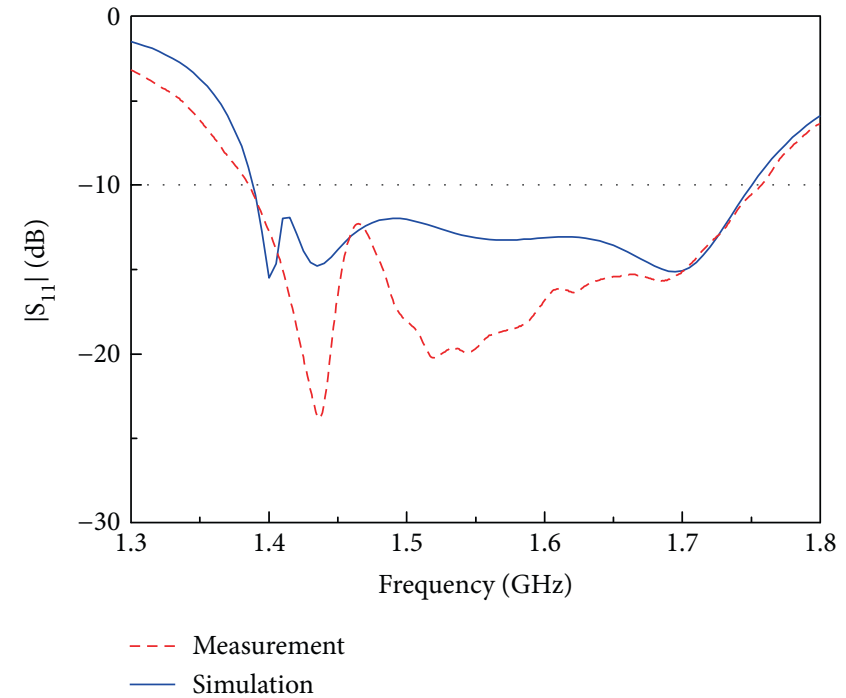

(a)



(b)

FIGURE 13: Simulations and measurements of the crossed-dipole antenna loaded with parasitic patches: (a) $\left|\mathrm{S}_{11}\right|$ and (b) AR and broadsidegain values.


(a)
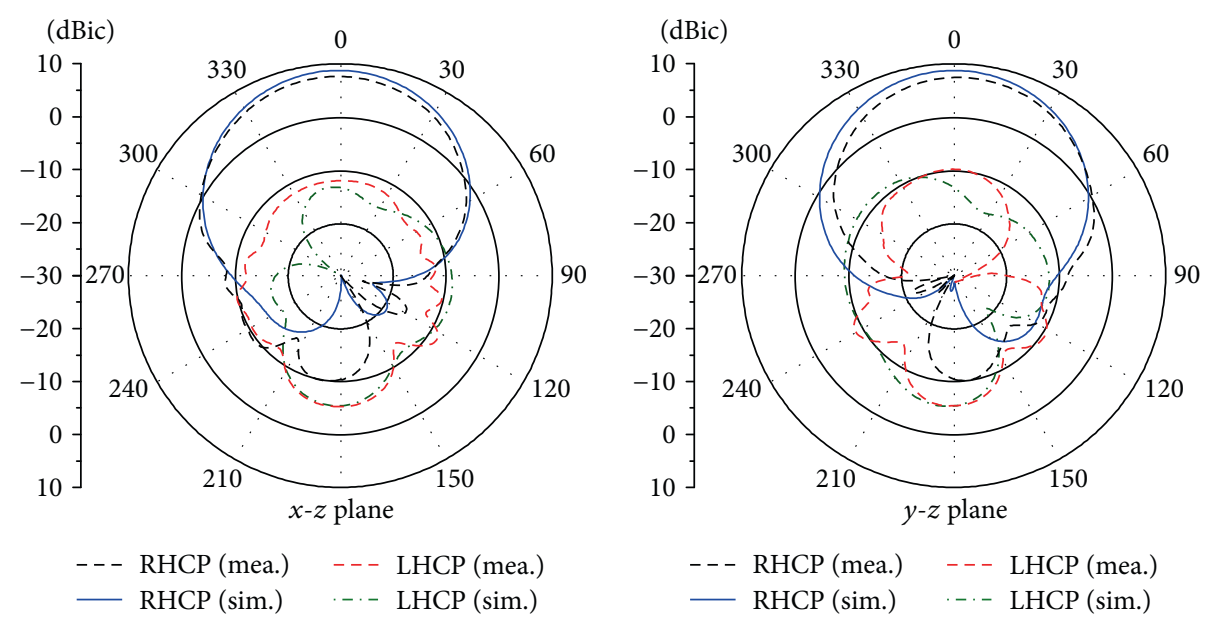

(b)

FIGURE 14: Simulations and measurements of the crossed-dipole antenna loaded with parasitic patches: (a) $1.52 \mathrm{GHz}$ and (b) $1.64 \mathrm{GHz}$ radiation patterns. 


\section{Conclusion}

An alternative approach to improving the performance of a planar antenna placed horizontally above a metallic ground plane and close to it has been proposed. The antenna comprises four parasitic patches placed between planar radiators and a ground plane. The radiator and parasitic patches are realized on thin substrates in order to achieve a low cost. The parasitic patches produce profile reduction, a shift of the resonance toward a lower frequency, and a significant improvement in the antenna bandwidth. These improvements validate both LP and CP designs, which is computationally and experimentally proved by investigating two different types of planar antenna radiators, including single-dipole and single-feed crossed-dipole antennas, loaded with parasitic patches. Compared to the previous designs, the proposed approach makes it easier to implement a lowprofile design, as well as broaden the antenna bandwidth, in particular at low frequencies.

\section{Conflicts of Interest}

The authors declare that there are no conflicts of interests regarding the publication of this manuscript.

\section{Acknowledgments}

This research is funded by the Vietnam National Foundation for Science and Technology Development (NAFOSTED) under Grant no. 102.04-2016.02. This research is also supported in part by the Institute for Information \& Communications Technology Promotion (IITP) grant funded by the Korean government (MSIP) (no. 2017-0-00959, University ICT Basic Research Lab) and "Human Resources Program in Energy Technology" of the KETEP granted financial resource from the Ministry of Trade, Industry \& Energy (no. 20164030201380).

\section{References}

[1] S. R. Best, "Improving the performance properties of a dipole element closely spaced to a PEC ground plane," IEEE Antennas and Wireless Propagation Letters, vol. 3, no. 1, pp. 359-363, 2004.

[2] D. Sievenpiper, L. Zhang, R. F. J. Broas, N. G. Alexopoulos, and E. Yablonovich, "High-impedance electromagnetic surfaces with a forbidden frequency band," IEEE Transactions on Microwave Theory and Techniques, vol. 47, no. 11, pp. 2059-2074, 1999.

[3] F. Yang and Y. Rahmat-Samii, "Reflection phase characterizations of the EBG ground plane for low profile wire antenna applications," IEEE Transactions on Antennas and Propagation, vol. 51, no. 10, pp. 2691-2703, 2003.

[4] H. Mosallaei and K. Sarabandi, "Antenna miniaturization and bandwidth enhancement using a reactive impedance substrate," IEEE Transactions on Antennas and Propagation, vol. 52, no. 9, pp. 2403-2414, 2004.

[5] S. Lim and M. F. Iskander, "Design of a dual-band, compact Yagi antenna over an EBG ground plane," IEEE Antennas and Wireless Propagation Letters, vol. 8, pp. 88-91, 2009.
[6] A. Vallecchi, J. R. De Luis, F. Capolino, and F. De Flaviis, "Low profile fully planar folded dipole antenna on a high impedance surface," IEEE Transactions on Antennas and Propagation, vol. 60, no. 1, pp. 51-62, 2012.

[7] I. T. McMichael, A. I. Zaghloul, and M. S. Mirotznik, "A method for determining optimal EBG reflection phase for low profile dipole antennas," IEEE Transactions on Antennas and Propagation, vol. 61, no. 5, pp. 2411-2417, 2013.

[8] M. F. Abedin and M. Ali, "Effect of EBG reflection phase profile on the input impedance and bandwidth of ultrathin directional dipoles," IEEE Transactions on Antennas and Propagation, vol. 53, no. 11, pp. 3664-3672, 2005.

[9] M. Z. Azad and M. Ali, "Novel wideband directional dipole antenna on a mushroom like EBG structure," IEEE Transactions on Antennas and Propagation, vol. 56, no. 5, pp. 12421250, 2008.

[10] F. Costa, O. Luukkonen, C. R. Simovski, A. Monorchio, S. A. Tretyakov, and P. M. Maagt, "TE surface wave resonances on high-impedance surface based antennas: analysis and modeling," IEEE Transactions on Antennas and Propagation, vol. 59, no. 10, pp. 3588-3596, 2011.

[11] Z. Chen, Y. Juan, X. Qing, and W. Che, "Enhanced radiation from a horizontal dipole closely placed above a PEC ground plane using a parasitic strip," IEEE Transactions on Antennas and Propagation, vol. 64, no. 11, pp. 4868-4871, 2016.

[12] S. X. Ta, I. Park, and R. W. Ziolkowski, "Crossed dipole antennas: a review," IEEE Antennas and Propagation Magazine, vol. 57, no. 5, pp. 107-122, 2015.

[13] M. F. Bolster, "A new type of circular polarizer using crossed dipoles," IRE Transactions on Microwave Theory and Techniques, vol. 9, no. 5, pp. 385-388, 1961.

[14] J. W. Baik, K. J. Lee, W. S. Yoon, T. H. Lee, and Y. S. Kim, "Circular polarized printed crossed dipole antennas with broadband axial ratio," Electronics Letters, vol. 44, no. 13, pp. 785-786, 2008.

[15] J. W. Baik, T. H. Lee, S. Pyo, S. M. Han, J. Jeong, and Y. S. Kim, "Broadband circularly crossed dipole with parasitic loop resonators and its array," IEEE Transactions on Antennas and Propagation, vol. 59, no. 1, pp. 80-88, 2011.

[16] H. H. Tran, I. Park, and T. K. Nguyen, "Circularly polarized bandwidth-enhanced crossed dipole antenna with a simple single parasitic element," IEEE Antennas and Wireless Propagation Letters, vol. 16, pp. 1-1779, 2017.

[17] Y. He, W. He, and H. Wong, "A wideband circularly polarized crossed-dipole antenna," IEEE Antennas and Wireless Propagation Letters, vol. 13, pp. 67-70, 2014.

[18] H. H. Tran and I. Park, "Wideband circularly polarized cavitybacked asymmetric crossed bowtie dipole antenna," IEEE Antennas and Wireless Propagation Letters, vol. 15, pp. 358$361,2016$.

[19] S. X. Ta and I. Park, "Dual-band operation of a circularly polarized radiator on finite artificial magnetic conductor surface," Journal of Electromagnetic Waves and Applications, vol. 28, no. 7, pp. 880-892, 2014.

[20] S. X. Ta and I. Park, "Artificial magnetic conductor based circularly polarized crossed-dipole antennas-part I: AMCstructure with grounding pins," Radio Science, vol. 52, no. 5, pp. 642-652, 2017.

[21] S. X. Ta and I. Park, "Artificial magnetic conductor based circularly polarized crossed-dipole antennas-part II: AMCstructure without grounding pins," Radio Science, vol. 52, no. 5, pp. 630-641, 2017. 


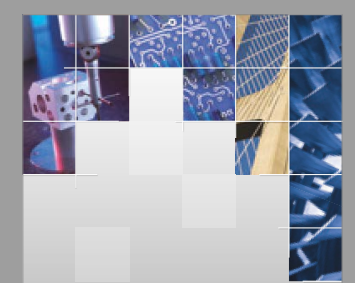

\section{Enfincering}
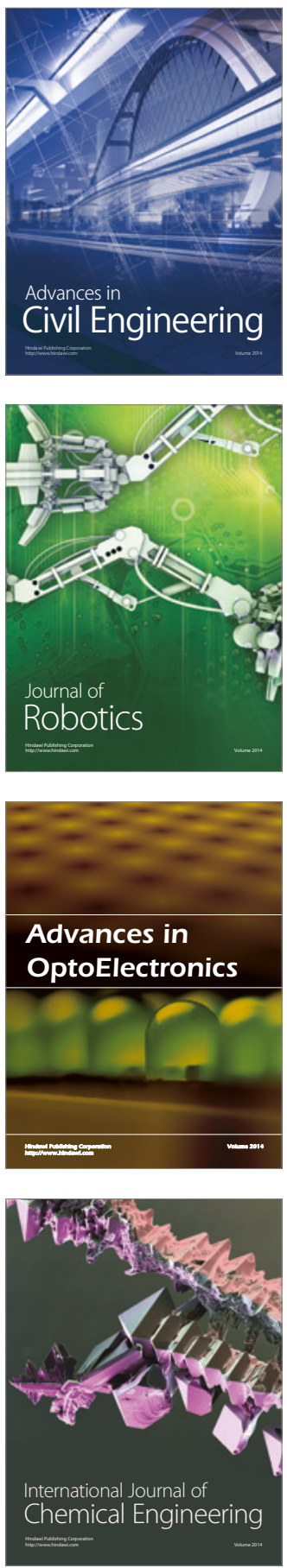

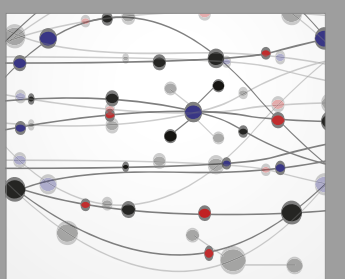

The Scientific World Journal

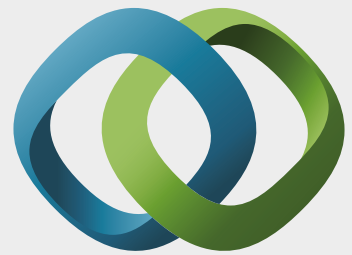

\section{Hindawi}

Submit your manuscripts at

https://www.hindawi.com
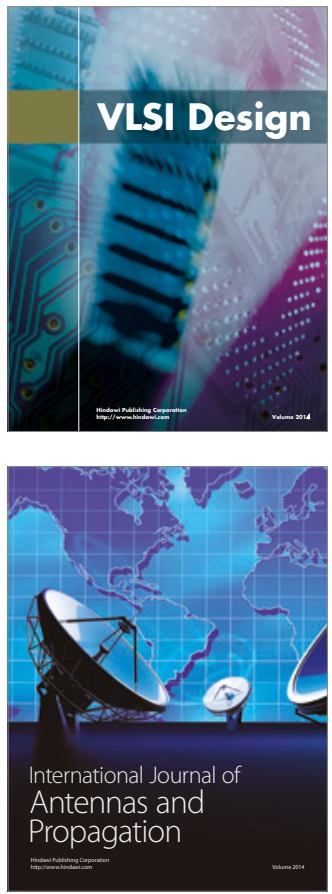

\section{Rotating}

Machinery
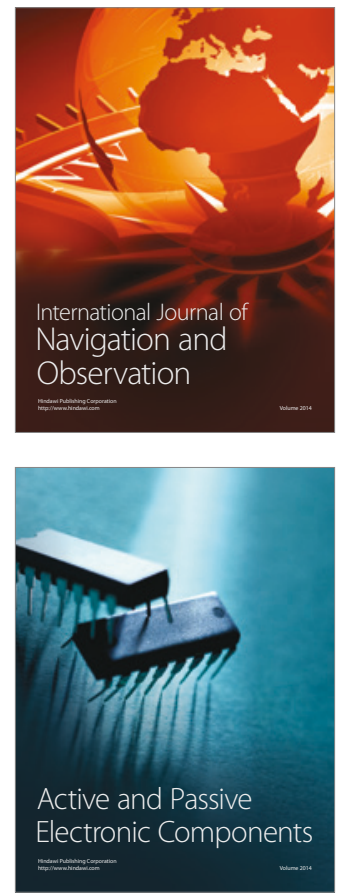
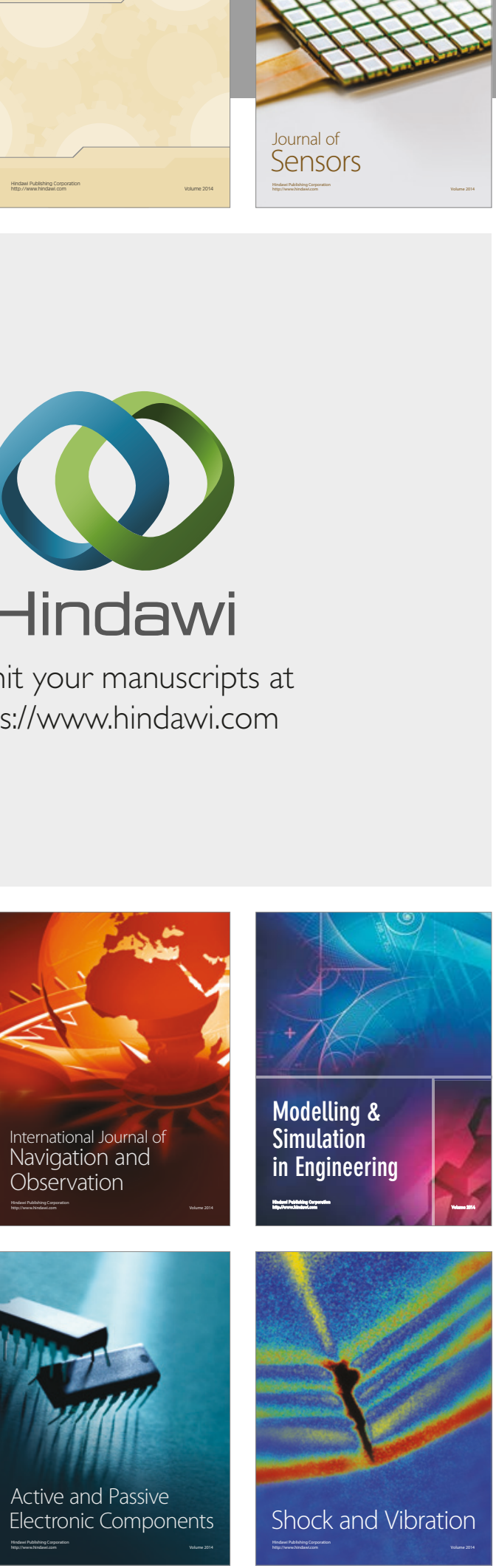


Distributed

Journal of

Control Science

and Engineering
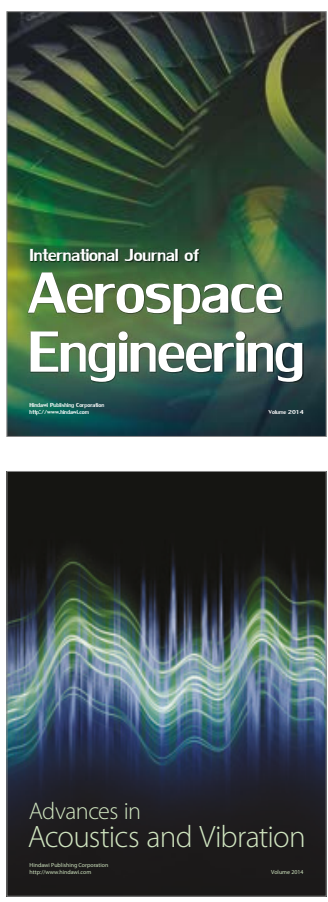

Sensor Networks 